\title{
Intrapulmonary Percussive Ventilation Superimposed on Conventional Mechanical Ventilation: Comparison of Volume Controlled and Pressure Controlled Modes
}

\author{
Guillaume Riffard, Julien Buzenet, and Claude Guérin MD PhD
}

\begin{abstract}
BACKGROUND: Previous bench studies suggest that dynamic hyperinflation may occur if intrapulmonary percussive ventilation (IPV) is superimposed on mechanical ventilation in volume controlled continuous mandatory ventilation (VC-CMV) mode. We tested the hypothesis that pressure controlled continuous mandatory ventilation (PC-CMV) can protect against this risk. METHODS: An ICU ventilator was connected to an IPV device cone adapter that was attached to a lung model (compliance $30 \mathrm{~mL} / \mathrm{cm} \mathrm{H}_{2} \mathrm{O}$, resistance $20 \mathrm{~cm} \mathrm{H} \mathrm{H}_{2} \mathrm{O} / \mathrm{L} / \mathrm{s}$ ). We measured inspired tidal volume $\left(V_{\text {TI }}\right)$ and lung pressure $\left(P_{\text {lung }}\right)$. Measurements were first taken with IPV off and the ICU ventilator set to VC-CMV or PC-CMV mode with a targeted $V_{T I}$ of $500 \mathrm{~mL}$. For each mode, an inspiratory time ( $\left.T_{I}\right)$ of 0.8 or $1.5 \mathrm{~s}$ and PEEP 7 or $15 \mathrm{~cm} \mathrm{H}_{2} \mathrm{O}$ were selected. The experiments were repeated with the IPV set to either 20 or 30 psi. The dependent variables were differences in $V_{T I}\left(\Delta V_{T I}\right)$ and $P_{\text {lung }}$ with IPV off or on. The effect of VC-CMV or PC-CMV mode was tested with the ICU ventilators for $T_{I}$, PEEP, and IPV working pressure using repeated measures of analysis of variance. RESULTS: At $T_{I} 0.8 \mathrm{~s}$ and $20 \mathrm{psi}, \Delta \mathrm{V}_{\mathrm{TI}}$ was significantly higher in VC-CMV than in PC-CMV. PEEP had no effect on $\Delta V_{T I^{*}}$ At $T_{I} 1.5 \mathrm{~s}$ and $20 \mathrm{psi}$ and at both $\mathrm{T}_{\mathrm{I}}$ values at each psi, mode and PEEP had a significant effect on $\Delta V_{T_{I}}$. With the ICU ventilators at $T_{I} 1.5 \mathrm{~s}$, PEEP $7 \mathrm{~cm} \mathrm{H} \mathrm{H}_{2} \mathrm{O}$, and $30 \mathrm{psi}, \Delta \mathrm{V}_{\mathrm{TI}}$ (mean $\pm \mathrm{SD}$ ) ranged from $-27 \pm 25$ to $-176 \pm 6 \mathrm{~mL}$ in PC-CMV and from $258 \pm 369$ to $369 \pm 16 \mathrm{~mL}$ in VC-CMV. The corresponding ranges were $-15 \pm 17$ to $-62 \pm 68 \mathrm{~mL}$ in PC-CMV and $26 \pm 21$ to $102 \pm 95 \mathrm{~mL}$ in VC-CMV at $\mathrm{T}_{\mathrm{I}} 0.8 \mathrm{~s}$, PEEP $7 \mathrm{~cm} \mathrm{H}_{2} \mathrm{O}$, and 20 psi. Similar findings pertained to $P_{\text {lung. }}$ CONCLUSIONS: When IPV is added to mechanical ventilation, the risk of hyperinflation is greater with $\mathrm{VC}-\mathrm{CMV}$ than with $\mathrm{PC}-\mathrm{CMV}$. We recommend using PC-CMV to deliver IPV and adjusting the trigger variable to avoid autotriggering. Key words: intrapulmonary percussive ventilation; volume controlled continuous mandatory ventilation; pressure controlled continuous mandatory ventilation; bench study; hyperinflation; lung model; mechanical ventilation. [Respir Care 2014;59(7):1116-1122. ( 2014 Daedalus Enterprises]
\end{abstract}

\section{Introduction}

Intrapulmonary percussive ventilation (IPV) delivers very small bursts of tidal volume $\left(\mathrm{V}_{\mathrm{T}}\right)$, usually less than the amount of physiologic dead space, at a high frequency, within the range of $60-600$ cycles/min. ${ }^{1}$ Furthermore, by providing a convective front of gas to the distal airways, IPV helps to move and clear respiratory secretions, ${ }^{2,3}$ resulting in: (1) increased mucus clearance, (2) better diffu-

\footnotetext{
The authors have disclosed no conflicts of interest.

Correspondence: Claude Guérin MD PhD, Service de Réanimation Médi-
cale, Groupement Hospitalier Nord, CHU de Lyon, 103 Grande Rue de
la Croix-Rousse, 69004 Lyon, France.E-mail: claude.guerin@ @chu-lyon.fr.

Correspondence: Claude Guérin MD PhD, Service de Réanimation Médi-
cale, Groupement Hospitalier Nord, CHU de Lyon, 103 Grande Rue de
la Croix-Rousse, 69004 Lyon, France.E-mail: claude.guerin@ @chu-lyon.fr.

Correspondence: Claude Guérin MD PhD, Service de Réanimation Médi-
cale, Groupement Hospitalier Nord, CHU de Lyon, 103 Grande Rue de
la Croix-Rousse, 69004 Lyon, France.E-mail: claude.guerin@ @chu-lyon.fr. DOI: $10.4187 /$ respcare.02727
}

Mr Riffard is affiliated with the Service de Réanimation Polyvalente, Hopital Nord, Centre Hospitalier Universitaire de Saint-Etienne, Saintd'Ingénieur de Lille, Lille, France. Dr Guérin is affiliated with the Service de Réanimation Médicale, Groupement Hospitalier Nord, Centre Hospitalier Universitaire de Lyon, Lyon, France.

www.rcjournal.com. 


\section{Bench Evaluation of Percussive Ventilation}

sion of oxygen and carbon dioxide into and from the alveoli, (3) higher values and more homogeneous distribution of alveolar ventilation, and (4) potential promotion of alveolar recruitment. It has been demonstrated using 3-dimensional lung imaging that a single IPV session in stable patients with COPD decreased airway resistance and increased airway volume regionally. ${ }^{4}$ As recently reviewed, ${ }^{5}$ IPV can be used either as a single treatment in spontaneously breathing patients ${ }^{6}$ or as adjunct therapy to mechanical ventilation. Five single-center randomized controlled trials testing IPV have been completed in different settings (Table 1). In patients with a COPD exacerbation, IPV was associated with a significant reduction in the need for noninvasive ventilation ${ }^{7}$ but with no change in the intubation rate for those who were treated by noninvasive ventilation. ${ }^{8}$ In patients with tracheotomies under mechanical ventilation, IPV was associated with better oxygenation and higher maximum static expiratory pressure. ${ }^{9}$ In patients with burn injury, IPV compared with volume controlled continuous mandatory ventilation (VC-CMV) improved oxygenation ${ }^{10}$ but did not reduce ventilator-free days. ${ }^{11}$ Although IPV is an unproven therapy regarding patient outcome, it is still used and, as such, should demonstrate greater benefit than harm.

When used in addition to conventional mechanical ventilation, a previous bench study warned about the risk of volutrauma. ${ }^{12}$ However, in this study, conventional mechanical ventilation was done in VC-CMV mode. Pressure controlled continuous mandatory ventilation (PCCMV) mode should better accommodate IPV ${ }^{13}$ and is the mode recommended by the manufacturer. ${ }^{14}$ The rationale relies on the basic functioning of a VC or PC breath ${ }^{15-17}$ and how PEEP is regulated. Because no study has systematically compared both modes with IPV added, we performed a bench investigation to compare VC-CMV and PC-CMV modes delivered by ICU ventilators with IPV superimposed. Our working hypothesis was that PC-CMV mode would be associated with a lower risk of volutrauma than VC-CMV mode.

\section{Methods}

\section{Equipment}

Our set-up comprised the following items: (1) a sliding air-entrainment percussive device (IPV2C, Phasitron, Percussionaire Corporation, Sandpoint, Idaho), which has been regularly used by the author (Guérin) in the ICU; (2) 5 ICU ventilators labeled A-E (Avea, CareFusion, San Diego, California; Engström Carestation, GE Healthcare, Madison, Wisconsin; Evita XL, Dräger, Lübeck, Germany; NPB 840, Covidien, Mansfield, Massachusetts; and Servo-i, Maquet, Wayne, New Jersey), respectively; (3) a single-lung configuration test lung (TTL, Michigan Instru-

\section{QUICK LOOK}

\section{Current knowledge}

Intrapulmonary percussive ventilation (IPV) may improve secretion clearance in mechanically ventilated patients. During volume controlled ventilation, the addition of IPV has been shown to increase lung volumes and cause dynamic hyperinflation, potentially risking lung injury.

\section{What this paper contributes to our knowledge}

When IPV is added to mechanical ventilation, the risk of hyperinflation is greater with volume controlled ventilation compared with pressure controlled ventilation. IPV pressure changes can also trigger the ventilator in both modes. Adjusting the trigger variable to avoid excessive triggering may also limit hyperinflation.

ments, Grand Rapids, Michigan) with adjustable compliance and resistance and port to directly measure the pressure inside the lung $\left(\mathrm{P}_{\text {lung }}\right)$; (4) a data acquisition system containing a bidirectional linear pneumotachometer (3813 series, Hans Rudolph, Shawnee, Kansas) for air flow (i) measurement and a straight connector (VBM Medizintechnik GmbH, Sulz am Neckar, Germany) to measure pressure at the airway opening $\left(\mathrm{P}_{\mathrm{ao}}\right)$. The pneumotachometer was linear over the $0-800 \mathrm{~L} / \mathrm{min} \dot{\mathrm{V}}$ range. The $\dot{\mathrm{V}}$, $\mathrm{P}_{\text {lung }}$, and $\mathrm{P}_{\text {ao }}$ ports were connected to piezoresistive transducers (BD Gabarit, Vogt Medical Vertrieb GmbH, Karlsruhe, Germany). The signals were amplified, sent to analog-digital hardware (Biopac MP150, Biopac Systems, Goleta, California), and recorded at $200 \mathrm{~Hz}$ (AcqKnowledge, Biopac Systems).

\section{Protocol}

The experiments were conducted over a 1-d period for each ICU ventilator in our laboratory at room temperature in ambient air. The piezoresistive transducers were calibrated before the measurements were taken using a rotameter flow meter (Martin Médical, Lyon, France) for $\dot{V}$ and a manometer (Fluke Corporation, Everett, Washington) for $\mathrm{P}_{\mathrm{ao}}$ and $\mathrm{P}_{\text {lung }}$.

The lung model was set to $30 \mathrm{~mL} / \mathrm{cm} \mathrm{H}_{2} \mathrm{O}$ compliance and $20 \mathrm{~cm} \mathrm{H}_{2} \mathrm{O} / \mathrm{L} / \mathrm{s}$ resistance. The inspiratory and expiratory lines of the ICU ventilator and IPV device were plugged into the cone adapter (Fig. 1). The latter was attached to the measurement set-up (Fig. 1). For each ICU ventilator, measurements were taken while IPV was randomly set either to on or off. Two levels of the IPV device 


\section{Bench Evaluation of Percussive Ventilation}

Table 1. $\Delta \mathrm{V}_{\mathrm{TI}}, \Delta \mathrm{P}_{\text {lung, } \mathrm{I}}$, and $\Delta \mathrm{P}_{\text {lung, E }}$ Values With Inspiratory Time Set to $1.5 \mathrm{~s}$ and Intrapulmonary Percussive Ventilation Set to $30 \mathrm{psi}$ Working Pressure for PC-CMV and VC-CMV Modes at 2 Levels of PEEP

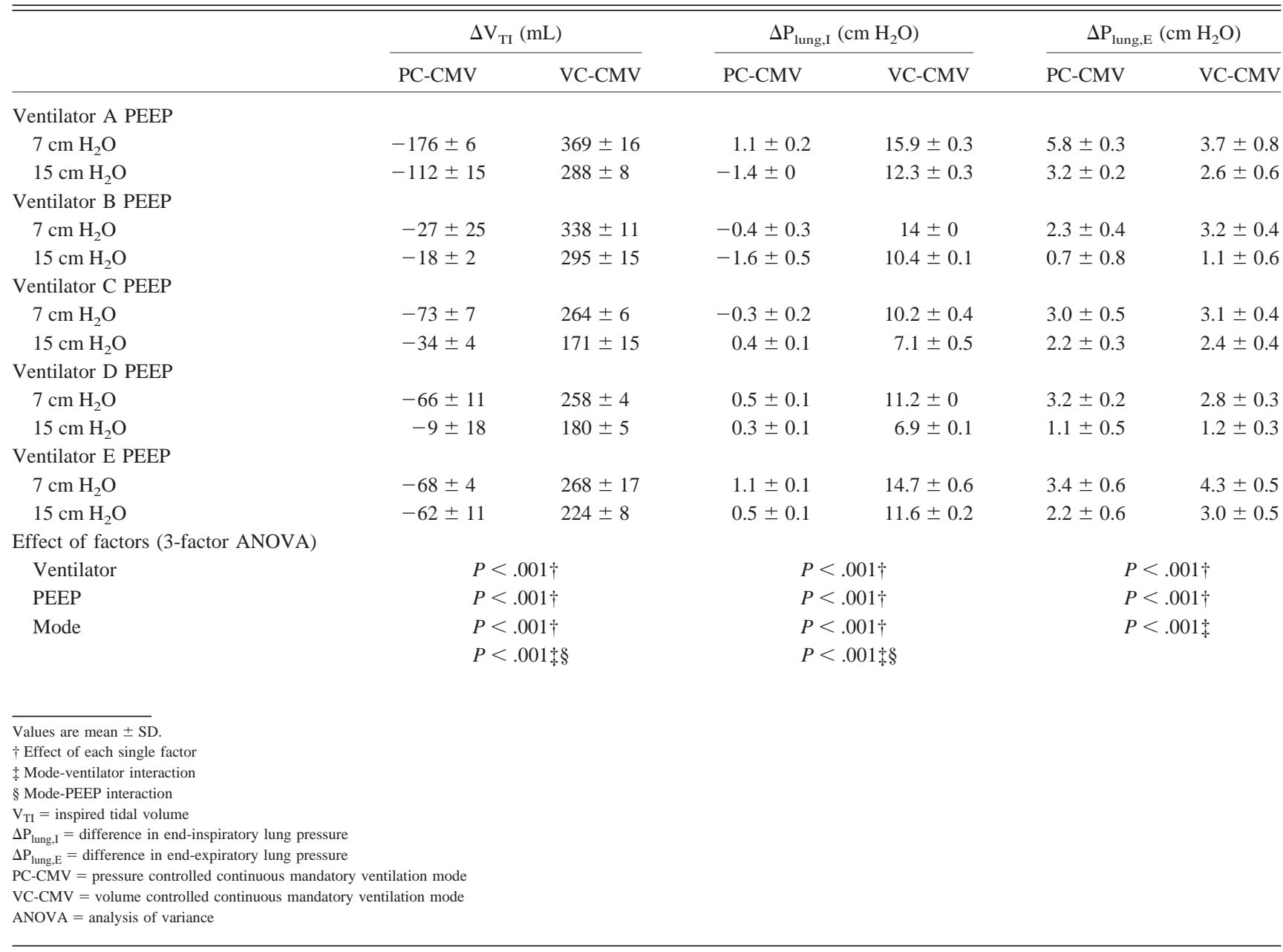

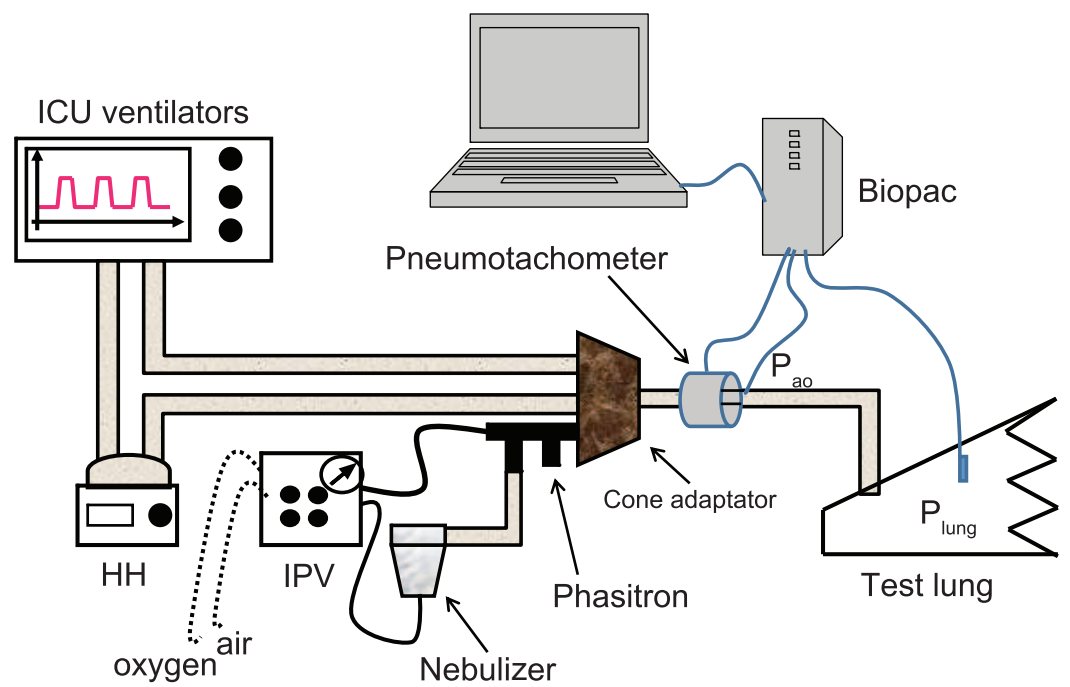

Fig. 1. Experimental set-up used in the present study. IPV $=$ intrapulmonary percussive ventilation. $\mathrm{HH}=$ heated humidifier. $\mathrm{P}_{\text {lung }}=$ lung pressure. $\mathrm{P}_{\mathrm{ao}}=$ pressure at the airway opening. 


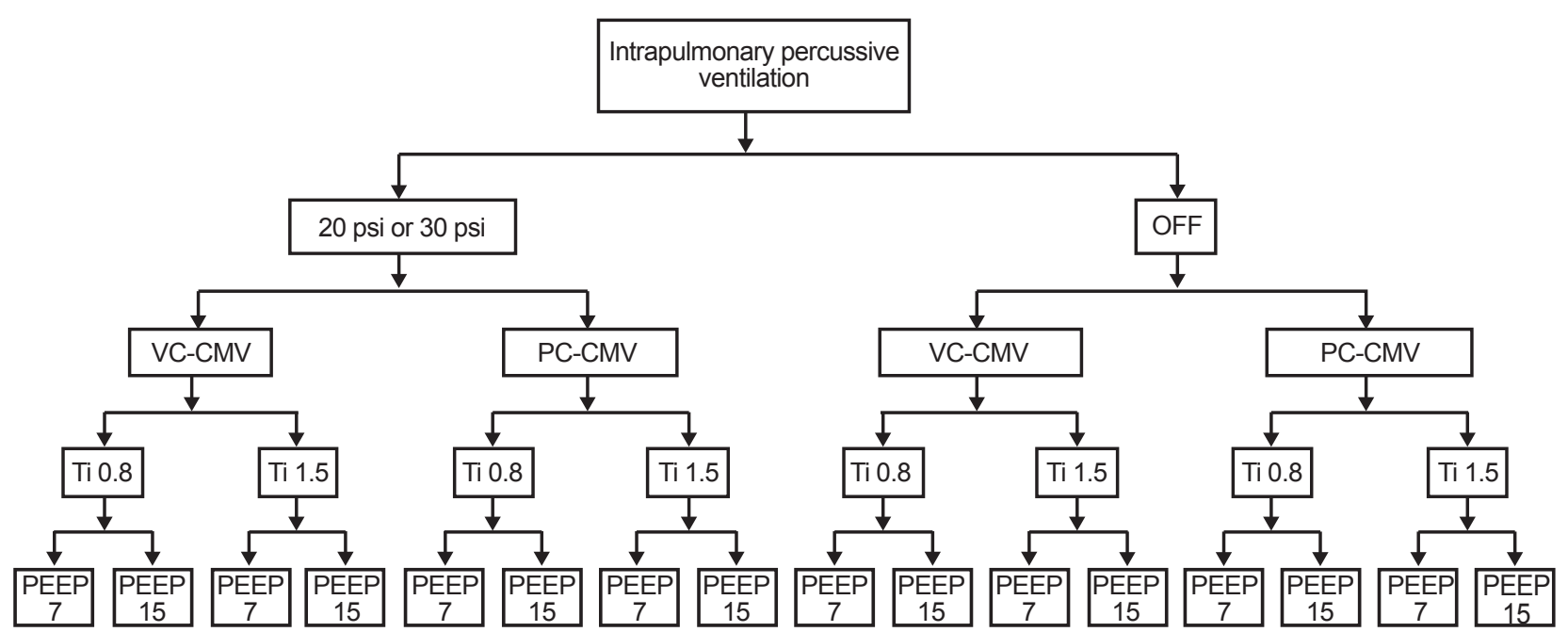

Fig. 2. Study design. IPV = intrapulmonary percussive ventilation. PC-CMV = pressure controlled continuous mandatory ventilation mode.VC-CMV = volume controlled continuous mandatory ventilation mode. $\mathrm{T}_{1}=$ inspiratory time.

working pressure were used (20 and $30 \mathrm{psi}$ ) and applied randomly. VC-CMV and PC-CMV modes were randomly applied to the ICU ventilator. In VC-CMV mode, constant flow inflation, a breathing frequency of 15 breaths $/ \mathrm{min}$, and targeted $\mathrm{V}_{\mathrm{T}}$ of $500 \mathrm{~mL}$ were used. In PC-CMV mode, the pressure was adjusted to reach the same targeted $\mathrm{V}_{\mathrm{T}}$ of $500 \mathrm{~mL}$. In both modes, $\mathrm{F}_{\mathrm{IO}_{2}}$ was set to 0.21 , the heated humidifier was off, no heat-and-moisture exchanger was inserted, and the trigger was adjusted to avoid autotriggered breaths (to $2-5 \mathrm{~L} / \mathrm{min}$ ). In each mode, PEEP of 7 and $15 \mathrm{~cm} \mathrm{H}_{2} \mathrm{O}$, and $\mathrm{T}_{\mathrm{I}}$ of 0.8 and $1.5 \mathrm{~s}$ were tested in a random order. Therefore, 4 combinations of IPV and ventilator mode were investigated: IPV off volume controlled, IPV on volume controlled, IPV off pressure controlled, IPV on pressure controlled. Furthermore, 4 combinations of $\mathrm{T}_{\mathrm{I}}$ and PEEP were applied to each of these initial combinations (Fig. 2). For each condition (ie, each cell in Fig. 2 ), $\dot{\mathrm{V}}, \mathrm{P}_{\mathrm{ao}}$, and $\mathrm{P}_{\text {lung }}$ signals were recorded for 10 breaths after a 1-min stabilization period.

\section{Data Analysis}

The last 3 respiratory cycles were retained for the analysis (Fig. 3). For each ICU ventilator, 24 combinations were generated ( 3 IPV working pressures [0 psi with IPV off, 20 and 30 psi with IPV on] $\times 2$ ICU ventilator modes $\times 2 \mathrm{~T}_{\mathrm{I}} \times 2$ PEEP levels) with 3 repetitions, making a total of 72 measurements. Inspired $\mathrm{V}_{\mathrm{T}}\left(\mathrm{V}_{\mathrm{TI}}\right)$ was obtained by digitally integrating the $\dot{V}$ signal.

The main outcome measure was the difference in $\mathrm{V}_{\mathrm{TI}}$ $\left(\Delta \mathrm{V}_{\mathrm{TI}}\right)$ between each IPV working pressure of 20 or $30 \mathrm{psi}$ and $0 \mathrm{psi}$ (IPV off). Negative values for $\Delta \mathrm{V}_{\mathrm{TI}}$ indicate that $\mathrm{V}_{\mathrm{TI}}$ is lower with IPV on than with IPV off. Conversely, positive values for $\Delta \mathrm{V}_{\mathrm{TI}}$ indicate that $\mathrm{V}_{\mathrm{TI}}$ is higher with
IPV on than with IPV off. The secondary outcome measures were the corresponding differences in peak end-inspiratory $\mathrm{P}_{\text {lung }}\left(\Delta \mathrm{P}_{\text {lung, },}\right)$ and end-expiratory $\mathrm{P}_{\text {lung }}\left(\Delta \mathrm{P}_{\text {lung, } \mathrm{E}}\right)$ and in the mean airway pressure measured over the whole breath cycle. The same interpretation of the sign for $\Delta \mathrm{V}_{\mathrm{TI}}$ values also applies to the sign of the values for $\Delta \mathrm{P}_{\text {lung,I }}$ and $\Delta \mathrm{P}_{\text {lung, } \mathrm{E}}$

\section{Statistical Analysis}

Four different experiments were compared: $\mathrm{T}_{\mathrm{I}} 0.8$ and $1.5 \mathrm{~s}$, each with 20 and 30 psi working pressure IPV. For each of these experiments, the dependent variables $\Delta \mathrm{V}_{\mathrm{TI}}$, $\Delta \mathrm{P}_{\text {lung, },}$, and $\Delta \mathrm{P}_{\text {lung, } \mathrm{E}}$ were compared between ventilator modes, taking into account interaction with the ventilator and the PEEP level using a 3-factor analysis of variance.

The values for $\Delta \mathrm{V}_{\mathrm{TI}}, \Delta \mathrm{P}_{\text {lung, } \mathrm{I}}$, and $\Delta \mathrm{P}_{\text {lung, } \mathrm{E}}$ were expressed as mean $\pm \mathrm{SD}$. Statistical analysis was carried out using R2.9.0 software. ${ }^{18} P<.05$ was set as the threshold for statistical significance.

\section{Results}

\section{$T_{I} 1.5 \mathrm{~s}$ and 30 psi Working Pressure}

As expected, the effect of the different factors investigated (mode, PEEP, and ventilator) was most striking for this part of the experiment because the longest $T_{I}$ and the highest IPV working pressure applied increased the differences between them. Therefore, these results are presented first. The mean values for $\Delta \mathrm{V}_{\mathrm{TI}}$ were systematically positive in VC-CMV mode and systematically negative in PC-CMV mode (see Table 1). Therefore, $\Delta \mathrm{V}_{\mathrm{TI}}$ was significantly higher with VC-CMV mode than with PC-CMV 

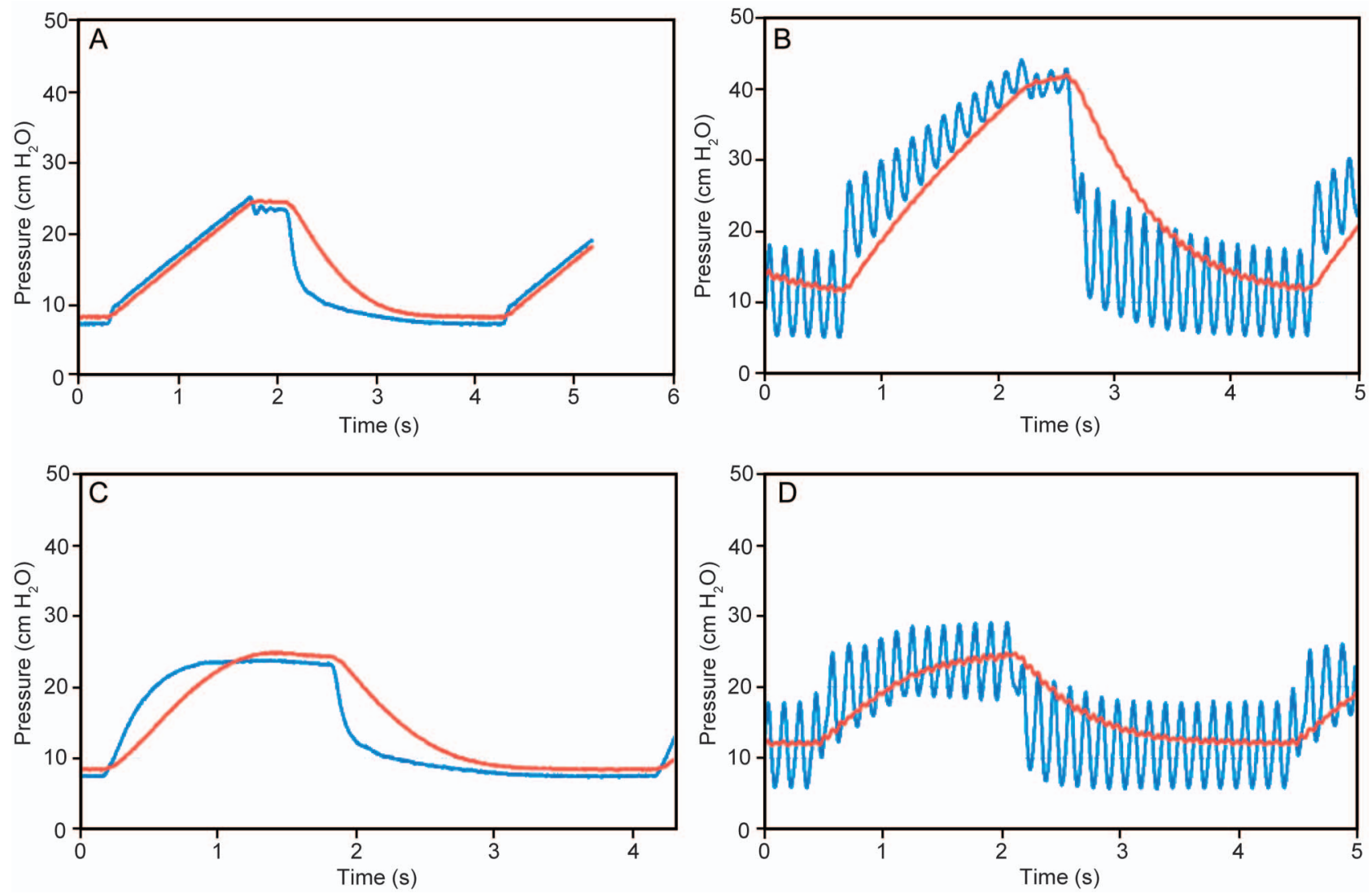

Fig. 3. Records of pressure at the airway opening (blue lines) and of lung pressure (red lines) obtained in pressure controlled continuous mandatory ventilation (PC-CMV) or volume controlled continuous mandatory ventilation (VC-CMV) mode with intrapulmonary percussive ventilation (IPV) either off or on. A: VC-CMV mode with IPV off. B: VC-CMV mode with IPV on. C: PC-CMV mode with IPV off. D: PC-CMV with IPV on. Inspiratory time of $1.5 \mathrm{~s}, 30 \mathrm{psi}$, and PEEP of $7 \mathrm{~cm} \mathrm{H} \mathrm{H}_{2} \mathrm{O}$ were selected.

mode. The magnitude of the difference in $\Delta \mathrm{V}_{\mathrm{TI}}$ between VC-CMV and PC-CMV modes and the absolute value of $\Delta \mathrm{V}_{\mathrm{TI}}$ in VC-CMV mode were both clinically relevant for each ICU ventilator and PEEP. The ICU ventilator and PEEP had a statistically significant effect on $\Delta \mathrm{V}_{\mathrm{TI}}$, as did their interaction with ventilator mode.

$\Delta \mathrm{P}_{\text {lung,I }}$ was significantly higher with $\mathrm{VC}-\mathrm{CMV}$ mode than with PC-CMV mode (Table 1). The magnitude of the difference in $\Delta \mathrm{V}_{\mathrm{TI}}$ between $\mathrm{VC}-\mathrm{CMV}$ and PC-CMV modes and the absolute value of $\Delta \mathrm{P}_{\text {lung,I }}$ in VC-CMV mode were both clinically relevant for each ICU ventilator and PEEP. The ICU ventilator and PEEP had a statistically significant effect on $\Delta \mathrm{P}_{\text {lung,I }}$, as did their interaction with ventilator mode. Mode had a significant effect on mean airway pressure. (See the supplementary materials at http://www. rcjournal.com.)

Ventilator mode had no statistically significant effect on $\Delta \mathrm{P}_{\text {lung,E }}$, whereas the ICU ventilator and PEEP did. There was a statistically significant interaction between the ventilator mode and the ICU ventilator.

\section{Other Combinations of $T_{I}$ and Working Pressure}

$\Delta \mathrm{V}_{\mathrm{TI}}$ was significantly higher with $\mathrm{VC}-\mathrm{CMV}$ mode than with PC-CMV mode for the 3 remaining combinations of $\mathrm{T}_{\mathrm{I}}$ and IPV working pressure $(0.8 \mathrm{~s}$ and $20 \mathrm{psi}, 0.8 \mathrm{~s}$ and $30 \mathrm{psi}$, and $1.5 \mathrm{~s}$ and $20 \mathrm{psi}$ ). (See the supplementary materials at http://www.rcjournal.com.) The ICU ventilator and PEEP (except for $\mathrm{T}_{\mathrm{I}} 0.8 \mathrm{~s}$ and 20 psi working pressure) had a significant effect on $\Delta \mathrm{V}_{\mathrm{TI}}$. The same held true for the interaction between mode and ventilator and between mode and PEEP.

The values for $\Delta \mathrm{P}_{\text {lung,I }}$ were statistically significantly different between ICU ventilator modes. (See the supplementary materials at http://www.rcjournal.com.) Some of these differences may be clinically important. The ICU ventilator and PEEP both had a statistically significant

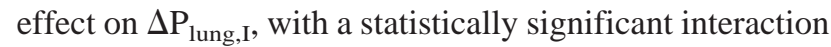
between mode and ICU ventilator and between mode and PEEP. 


\section{Bench Evaluation of Percussive Ventilation}

The same was true for $\Delta \mathrm{P}_{\text {lung, } \mathrm{E}}$, except for a lack of interaction between mode and PEEP at $T_{\mathrm{I}} 1.5 \mathrm{~s}$ and $20 \mathrm{psi}$ IPV working pressure. (See the supplementary materials at http://www.rcjournal.com.) However, the differences between the ICU ventilator modes for any given PEEP and ICU ventilator may not be clinically relevant, except for the highest IPV working pressure. Mode had no significant effect on mean airway pressure at $\mathrm{T}_{\mathrm{I}} 0.8 \mathrm{~s}$ and $20 \mathrm{psi}$ working pressure. (See the supplementary materials at http://www.rcjournal.com.)

\section{Discussion}

We found that the risk for lung hyperinflation at the end of inspiration can be greater when IPV is used with VCCMV mode compared with PC-CMV mode, thus confirming our working hypothesis. This result was predictable given the basic functioning of VC-CMV and PC-CMV modes as briefly summarized below. The equation of motion of the respiratory system is an appropriate tool to better understand the interaction between CMV and IPV:

$$
\mathrm{P}_{\mathrm{RS}}=\mathrm{P}_{\mathrm{mus}}+\mathrm{P}_{\mathrm{vent}}=\mathrm{EV}+\mathrm{R}_{\mathrm{RS}} \dot{\mathrm{V}}
$$

where $\mathrm{P}_{\mathrm{RS}}$ is the total pressure applied to the respiratory system, $\mathrm{P}_{\text {mus }}$ is the pressure generated by the contraction of inspiratory muscles, $\mathrm{P}_{\text {vent }}$ is the ventilator pressure, $\mathrm{E}$ is the elastance of the respiratory system, $\mathrm{V}$ is the change in lung volume above end-expiratory lung volume, and $R_{R S}$ is the resistance of the respiratory system. In a sedated and paralyzed patient, $\mathrm{P}_{\text {mus }}=0$, and hence, $\mathrm{P}_{\mathrm{RS}}$ is equal to $\mathrm{P}_{\text {vent }}$.

In VC-CMV mode, the ventilator flow is controlled, not the pressure (which depends on lung compliance and resistance); thus, adding IPV (a source of flow) should affect the $\mathrm{V}_{\mathrm{TI}}$ delivered: the more flow, the more $\mathrm{V}_{\mathrm{TI}}$, the more pressure. By adding an IPV device to a ventilator in VCCMV mode, the ventilator will have issues measuring and adjusting the $\mathrm{V}_{\mathrm{TI}}$ delivered. This is particularly true if the flow is inserted after the inhalation valve. In fact, as demonstrated by this study, the ventilators could not adjust it.

In PC-CMV mode, the mechanical breath pressure $\left(\mathrm{P}_{\text {vent }}\right.$ in Equation 1) is controlled, not the $\mathrm{V}_{\mathrm{TI}}$ and flow (which are dependent on lung compliance and resistance); thus, adding IPV (a source of flow) should not affect $P_{\text {vent }}$ but will affect the flow and $\mathrm{V}_{\text {TI }}$ delivered. In this study, we found that actually adding IPV decreased flow and $\mathrm{V}_{\mathrm{TI}}$ delivered. By adding IPV to a ventilator in PC-CMV mode, the ventilator will try to maintain the preset airway pressure $\left(\mathrm{P}_{\mathrm{vent}}\right.$ in Equation 1). Thus, the addition of flow and pressure to the ventilator circuit will lead the ventilator to decrease flow to maintain $\mathrm{P}_{\text {vent }}$, and the $\mathrm{V}_{\mathrm{TI}}$ delivered will decrease.

\section{Changes in $\mathbf{V}_{\text {TI }}$ and $P_{\text {lung, } I}$}

In VC-CMV mode, the magnitude of the absolute changes in $\mathrm{V}_{\mathrm{TI}}$ and $\mathrm{P}_{\text {lung, } \mathrm{I}}$ regularly increased with increasing $\mathrm{T}_{\mathrm{I}}$ and working pressure. In contrast, in PC-CMV mode, the changes in $\mathrm{V}_{\mathrm{TI}}$ were consistently negative, as were those pertaining to $P_{\text {lung,I }}$ except in some rare instances: the longer the $T_{I}$, the longer the exposure to $\dot{V}$ and hence the longer the exposure to the considerations discussed above.

The risk of hyperinflation at the end of inspiration is greater with VC-CMV than with PC-CMV, and hence, the ICU ventilator should be set to PC-CMV mode when IPV is used in conjunction with mechanical ventilation. We found statistically significant differences among the $5 \mathrm{ICU}$ ventilators tested, although these differences may not be clinically relevant. However, with ICU ventilator A, there was a risk of reducing alveolar ventilation and promoting alveolar derecruitment once IPV was turned on, in particular with the longest $T_{I}$ and highest working pressure IPV. Tsuruta et $\mathrm{al}^{13}$ superimposed IPV on PC-CMV in 10 obese subjects who exhibited refractory compression atelectasis and hypoxemia after abdominal surgery. $\mathrm{P}_{\mathrm{aO}} / \mathrm{F}_{\mathrm{IO}_{2}}$ went up from $189 \pm 63$ to $243 \pm 67 \mathrm{~mm} \mathrm{Hg} 3 \mathrm{~h}$ after IPV onset, an improvement that was maintained over $24 \mathrm{~h}$. As shown on the lung computed tomography scan done after $24 \mathrm{~h}$ of IPV, the dorsal lung regions, which were atelectatic before IPV, became re-aerated. Therefore, the improvement in oxygenation could be due to dorsal lung recruitment induced by IPV. Because this study was not controlled, these findings could also be explained by other factors such as the spontaneous resolution of atelectasis over time. Dellamonica et al $^{12}$ argued that these results could stem from an increase in lung volume. Our present data indicate that this would not be the case, as the $\mathrm{V}_{\mathrm{TI}}$ did not increase with IPV when used in PC-CMV mode.

\section{Change in $\mathbf{P}_{\text {lung, } \mathbf{E}}$}

In this study, we did not use PEEP of $0 \mathrm{~cm} \mathrm{H}_{2} \mathrm{O}$. This decision conforms to the results of previous bench studies $^{12}$ and with the manufacturer's recommendations (http:// www.percussionaire.com/A50474-2alog.asp). Once IPV was started, $\mathrm{P}_{\text {lung,E }}$ systematically increased for each mode, with a statistically but probably not clinically significant difference between VC-CMV and PC-CMV. For the $\mathrm{T}_{\mathrm{I}}$ $1.5 \mathrm{~s} / 30 \mathrm{psi}$ IPV working pressure combination (Table 1), the ventilator mode had no statistical effect on the change in $\mathrm{P}_{\text {lung,E }}$, a result that could be explained by the high lung elastance set, which may have minimized the increase in $\mathrm{P}_{\text {lung,E}}$. The differences in $\mathrm{P}_{\text {lung,E }}$ were statistically significant across the ventilators and these differences were clinically relevant. In particular, ventilator A was associated 
with the highest value of change in $\mathrm{P}_{\text {lung,E }}$ in PC-CMV mode.

We noted that the effect on PEEP was not different between VC-CMV and PC-CMV modes. The reason is that PEEP is a pressure controlled phase. Thus, the ventilator will drop the pressure to the set PEEP and will attempt to maintain the pressure at the same level. Thus, the fluctuations by the IPV would result in a decrease in $\mathrm{P}_{\text {vent }}$ to maintain the same PEEP. Thus, examination of several levels of PEEP had no clear effect.

\section{Clinical Implications}

The present data recommend setting the ventilator mode to PC-CMV rather than VC-CMV using $\mathrm{T}_{\mathrm{I}} 0.8 \mathrm{~s}$ when IPV is added. The reader should be aware that once IPV is superimposed on conventional mechanical ventilation, the monitoring of delivered volume is no longer reliable. This was the case with each of the 5 ICU ventilators we tested.

\section{Limitations}

The main limitation of this study is that as an in vitro investigation, the results cannot be translated to patients. In particular, this type of study cannot assess the hemodynamic effects of the different combinations tested. Another limitation is that we tested a single combination of lung compliance and resistance. It has been shown that pressure and volume delivered by IPV are influenced by changes in lung compliance and resistance. ${ }^{19}$

In conclusion, as suggested by this bench study, when the trigger of the ICU ventilators is adjusted to avoid any autotriggered breath, the PC-CMV mode should be selected when using IPV in combination with conventional mechanical ventilation.

\section{REFERENCES}

1. Lucangelo U, Fontanesi L, Antonaglia V, Pellis T, Berlot G, Liquori $\mathrm{G}$, et al. High frequency percussive ventilation (HFPV). Principles and technique. Minerva Anestesiol 2003;69(11):841-848, 848-851. Article in English and Italian.

2. Riffard G, Toussaint M. [Indications for intrapulmonary percussive ventilation (IPV): a review of the literature]. Rev Mal Respir 2012; 29(2):178-190. Article in French.

3. Riffard G, Toussaint M. [Intrapulmonary percussion ventilation: operation and settings]. Rev Mal Respir 2012;29(2):347-354. Article in French.
4. Ides K, Vos W, De Backer L, Vissers D, Claes R, Leemans G, et al. Acute effects of intrapulmonary percussive ventilation in COPD patients assessed by using conventional outcome parameters and a novel computational fluid dynamics technique. Int J Chron Obstruct Pulmon Dis 2012;7:667-671.

5. Kallet RH. Adjunct therapies during mechanical ventilation: airway clearance techniques, therapeutic aerosols, and gases. Respir Care 2013;58(6):1053-1073.

6. Toussaint M, De Win H, Steens M, Soudon P. Effect of intrapulmonary percussive ventilation on mucus clearance in Duchenne muscular dystrophy patients: a preliminary report. Respir Care 2003; 48(10):940-947.

7. Vargas F, Bui HN, Boyer A, Salmi LR, Gbikpi-Benissan G, Guenard $\mathrm{H}$, et al. Intrapulmonary percussive ventilation in acute exacerbations of COPD patients with mild respiratory acidosis: a randomized controlled trial [ISRCTN17802078]. Crit Care 2005;9(4):R382-R389.

8. Antonaglia V, Ferluga M, Molino R, Lucangelo U, Peratoner A, Roman-Pognuz E, et al. Comparison of noninvasive ventilation by sequential use of mask and helmet versus mask in acute exacerbation of chronic obstructive pulmonary disease: a preliminary study. Respiration 2011;82(2):148-154.

9. Clini EM, Antoni FD, Vitacca M, Crisafulli E, Paneroni M, ChezziSilva S, et al. Intrapulmonary percussive ventilation in tracheostomized patients: a randomized controlled trial. Intensive Care Med 2006;32(12):1994-2001.

10. Reper P, Wibaux O, Van Laeke P, Vandeenen D, Duinslaeger L, Vanderkelen A. High frequency percussive ventilation and conventional ventilation after smoke inhalation: a randomised study. Burns 2002;28(5):503-508.

11. Chung KK, Wolf SE, Renz EM, Allan PF, Aden JK, Merrill GA, et al. High-frequency percussive ventilation and low tidal volume ventilation in burns: a randomized controlled trial. Crit Care Med 2010; 38(10):1970-1977.

12. Dellamonica J, Louis B, Lyazidi A, Vargas F, Brochard L. Intrapulmonary percussive ventilation superimposed on conventional ventilation: bench study of humidity and ventilator behaviour. Intensive Care Med 2008;34(11):2035-2043.

13. Tsuruta R, Kasaoka S, Okabayashi K, Maekawa T. Efficacy and safety of intrapulmonary percussive ventilation superimposed on conventional ventilation in obese patients with compression atelectasis. J Crit Care 2006;21(4):328-332.

14. Percussionaire. A50-474-2 algorithm. http://www.percussionaire. com/A50474-2alog.asp. Accessed May 8, 2014.

15. Branson RD, Chatburn RL. Technical description and classification of modes of ventilator operation. Respir Care 1992;37(9):1026-1044.

16. Chatburn RL. Understanding mechanical ventilators. Expert Rev Respir Med 2010;4(6):809-819.

17. Chatburn RL. Classification of ventilator modes: update and proposal for implementation. Respir Care 2007;52(3):301-323.

18. R Development Core Team. R: a language and environment for statistical computing. Vienna: R Foundation for Statistical Computing; 2009. http://www.r-project.org. Accessed May 8, 2014.

19. Lucangelo U, Antonaglia V, Zin WA, Fontanesi L, Peratoner A, Bird FM, Gullo A. Effects of mechanical load on flow, volume and pressure delivered by high-frequency percussive ventilation. Respir Physiol Neurobiol 2004;142(1):81-91. 